\title{
Diameters of the thoracic aorta throughout life as measured with helical computed tomography
}

Alfred Hager, MD

Harald Kaemmerer, MD, VD, $\mathrm{PhD}^{\mathrm{a}}$

Ulrike Rapp-Bernhardt, MD $^{\text {b }}$

Sebastian Blücher, MD ${ }^{\mathrm{a}}$

Karl Rapp ${ }^{\mathrm{a}}$

Thomas M. Bernhardt, MD ${ }^{\mathrm{b}}$

Michael Galanski, MD, $\mathrm{PhD}^{\mathrm{c}}$

John Hess, MD, PhDa
From the Department of Pediatric Cardiology and Congenital Heart Disease, Deutsches Herzzentrum München, Technische Universität München, München, ${ }^{a}$ the Department of Diagnostic Radiology, Ottovon-Guericke Universität Magdeburg, Magdeburg, ${ }^{\mathrm{b}}$ and the Department of Diagnostic Radiology, Medizinische Hochschule Hannover, Hannover, ${ }^{\mathrm{c}}$ Germany.

Supported by Herzkind eV, Braunschweig, Germany.

Received for publication April 30, 2001; revisions requested July 30,2001 ; revisions received Oct 4, 2001; accepted for publication Nov 1, 2001.

Address for reprints: Alfred Hager, MD, Department of Pediatric Cardiology and Congenital Heart Disease, Deutsches Herzzentrum München, Technische Universität München, Lazarettstr 36, D-80636, München, Germany (E-mail: hager@dhm.mhn. de).

J Thorac Cardiovasc Surg 2002;123:1060-6

Copyright $\odot 2002$ by The American Association for Thoracic Surgery

$0022-5223 / 2002 \$ 35.00+0 \quad \mathbf{1 2 / 1 / 1 2 2 3 1 0}$

doi:10.1067/mtc.2002.122310
Objective: The use of helical computed tomography is well established in the evaluation of the thoracic aorta. Nevertheless, normal diameters and their changes during adult life according to this method are not available. We planned to set up normal diameters for the thoracic aorta of adults obtained by helical computed tomography.

Methods: Seventy adults, 17 to 89 years old, without any signs of cardiovascular disease were investigated with helical computed tomography. Aortic diameters were measured at seven predefined thoracic levels.

Results: Aortic diameters (mean \pm SD) were $2.98 \pm 0.46 \mathrm{~cm}$ at the aortic valve sinus, $3.09 \pm 0.41 \mathrm{~cm}$ at the ascending aorta, $2.94 \pm 0.42 \mathrm{~cm}$ proximal to the innominate artery, $2.77 \pm 0.37 \mathrm{~cm}$ at the proximal transverse arch, $2.61 \pm 0.41 \mathrm{~cm}$ at the distal transverse arch, $2.47 \pm 0.40 \mathrm{~cm}$ at the isthmus, and $2.43 \pm 0.35 \mathrm{~cm}$ at the diaphragm. Men had slightly longer diameters than did women. All diameters increased with age. There was no influence of weight, height, or body surface area. After normalization to the diameter at diaphragmatic level, no statistically significantly influential factor could be detected.

Conclusions: This study delineates normal intrathoracic aortic diameters for helical computed tomography, including relationships with sex and age. Pathologic dimensions of the aorta should preferably be provided as percentiles or $z$ scores.

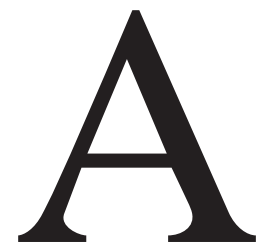

fter the introduction of helical computed tomography (CT) in the late 1980s, imaging of the aorta soon became a routine procedure for evaluation of the aorta in patients with aortic dissection, stenosis, or aneurysm formation. ${ }^{1,2}$ Furthermore, such imaging has increasingly been used for the assessment of aortic involvement in adult patients with connective tissue disease or congenital aortic diseases such as coarctation ${ }^{3-8}$ to quantify an additional hypoplastic aortic arch or a dilated ascending aorta. However, there are no reference data regarding thoracic aortic diameters according to helical CT to help characterize the physiologic range of aortic dimensions. This is regrettable, because the development of new imaging modalities makes setting up reference data essential, and helical CT provides excellent accuracy and reproducibility.

In the absence of reference data, it has often been suggested that diameter ratios normalized to those of the ascending aorta or the descending aorta at the diaphragmatic level be used for the definition of aortic stenosis or dilatation. ${ }^{3,9}$ This strategy is subject to discussion, however, because the aorta may show pathologic diameters 
TABLE 1. Demographic data of patients

\begin{tabular}{|c|c|c|c|}
\hline & Female & Male & Total \\
\hline No. & 24 & 46 & 70 \\
\hline $\begin{array}{l}\text { Age (y) } \\
\text { Mean } \pm \text { SD } \\
\text { Range }\end{array}$ & $\begin{array}{c}49.6 \pm 19.1 \\
17-89\end{array}$ & $\begin{array}{c}50.5 \pm 15.2 \\
19-77\end{array}$ & $\begin{array}{c}50.2 \pm 16.5 \\
17-89\end{array}$ \\
\hline $\begin{array}{l}\text { Weight }(\mathrm{kg}) \\
\text { Mean } \pm \text { SD } \\
\text { Range }\end{array}$ & $\begin{array}{c}64.3 \pm 14.9 \\
41-104\end{array}$ & $\begin{array}{c}77.6 \pm 14.2 \\
46-106\end{array}$ & $\begin{array}{c}73.1 \pm 15.7 \\
41-106\end{array}$ \\
\hline $\begin{array}{l}\text { Height }(\mathrm{cm}) \\
\text { Mean } \pm \text { SD } \\
\text { Range }\end{array}$ & $\begin{array}{c}165.9 \pm 6.6 \\
150-179\end{array}$ & $\begin{array}{c}175.8 \pm 7.3 \\
159-199\end{array}$ & $\begin{array}{c}172.4 \pm 8.2 \\
150-199\end{array}$ \\
\hline $\begin{array}{l}\text { Body surface area }\left(\mathrm{m}^{2}\right) \\
\text { Mean } \pm \mathrm{SD} \\
\text { Range }\end{array}$ & $\begin{array}{c}1.70 \pm 0.19 \\
1.33-2.15\end{array}$ & $\begin{array}{c}1.93 \pm 0.19 \\
1.62-2.43\end{array}$ & $\begin{array}{c}1.85 \pm 0.22 \\
1.33-2.43\end{array}$ \\
\hline
\end{tabular}

at the chosen reference levels and because these ratios vary with age, even in adults. ${ }^{10,11}$ This study was designed to define reference values obtained by helical CT for the normal thoracic aorta in adults and to analyze their relationship with sex, age, weight, height, and body surface area.

\section{Material and Methods}

\section{Patients}

Aortic diameters were prospectively measured in 70 consecutive adults who underwent a thoracic helical CT study for various noncardiovascular reasons. Patients with signs of cardiovascular disease were excluded. Demographic data are shown in Table 1.

\section{Measurements}

Aortic diameters were measured at seven intrathoracic levels: aortic valve sinus, ascending aorta at its maximum size, aorta just proximal the right innominate artery, proximal transverse aortic arch, distal transverse aortic arch, aortic isthmus, and aorta at the level of the diaphragmatic wall of the left ventricle (Figure 1). Relative aortic diameters-normalized to the diaphragmatic level-were calculated by dividing a given aortic diameter by the aortic diameter at the diaphragmatic level.

\section{Image Acquisition}

Helical CT scans were performed on a Somatom Plus (Siemens AG, Medical Engineering, Forchheim, Germany). Contrast scans were acquired after an antecubital intravenous injection of 80 to $100 \mathrm{~mL}$ of a nonionic contrast medium (Ultravist 300; Schering AG, Berlin, Germany) containing 300-mg/mL iodine. The injection rate was 1.5 to $3 \mathrm{~mL} / \mathrm{s}$. The helical CT scan was performed with a delay of 20 to 25 seconds after starting the injection.

The scan of the entire thorax was performed during a single held breath. The tube detector unit was rotating continuously at 1 to 1.3 rotations per second. Slice collimation was $5 \mathrm{~mm}$, table speed was 8 to $10 \mathrm{~mm} / \mathrm{s}$ in the caudocranial direction, and total scanning time was 25 to 30 seconds for the total longitudinal coverage from the sinus up to the apex of the pleural cavity.

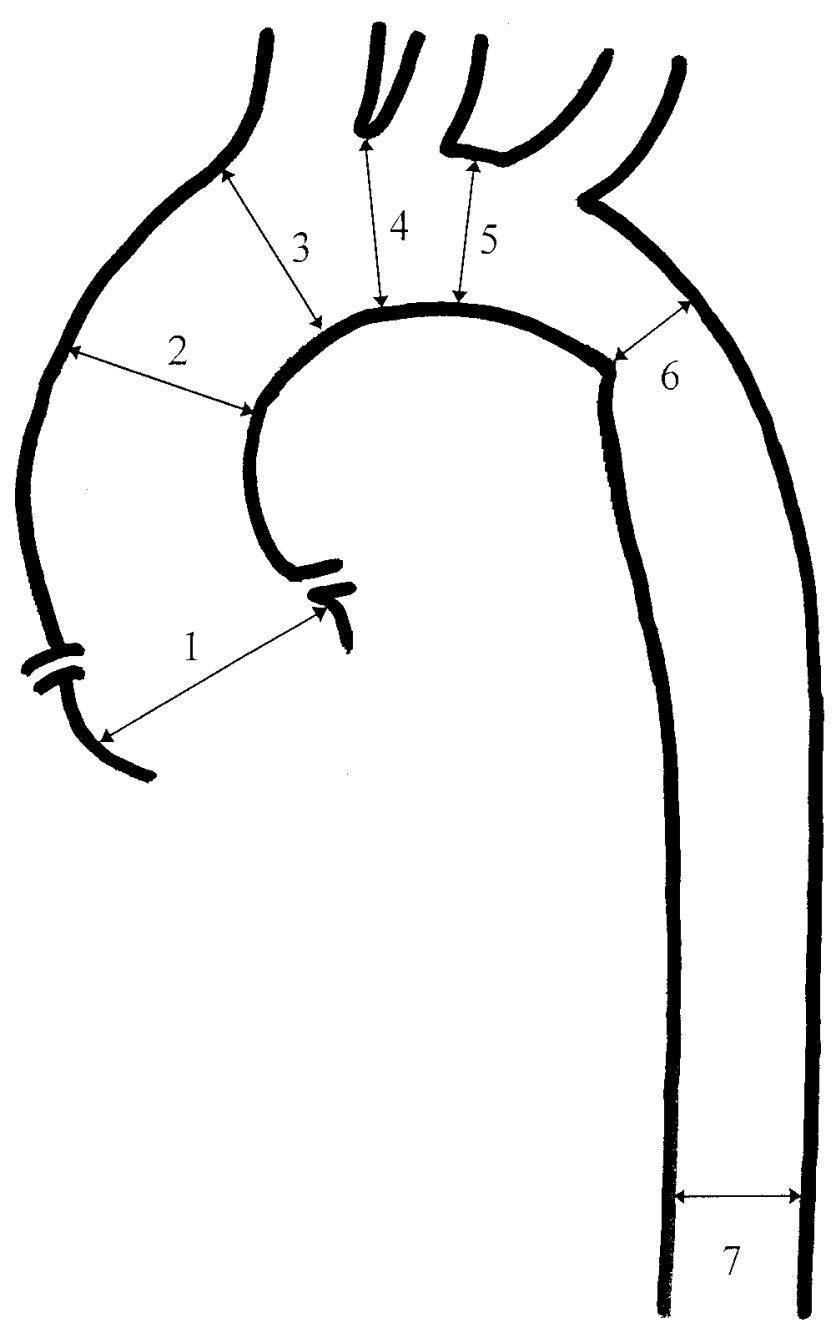

Figure 1. Levels of measured aortic diameters: 1, Aortic valve sinus; 2, ascending aorta; 3 , aorta proximal to innominate artery; 4, proximal transverse aortic arch; 5, distal transverse aortic arch; 6, aortic isthmus; 7 , descending aorta at level of diaphragmatic wall of left ventricle.

\section{Image Analysis}

Reconstruction was achieved every $4 \mathrm{~mm}$ with the $180^{\circ}$ linear interpolation algorithm. Multiplanar reconstruction was generated on a Magic View workstation (Siemens Medical Systems, Erlangen, Germany). The slices were manually adjusted for each aortic level to get an oblique plane strictly perpendicular to the course of the aorta. The internal diameter of the vessel was measured with an electronic caliper in three different directions. The arithmetic mean of those three estimates was used for further calculations. All images were reconstructed and analyzed by an experienced observer (U.R.-B., S.B., T.B.).

\section{Statistical Analysis}

Measurements were stored in a database and exported to a statistical software package (StatView; SAS Institute, Inc, Cary, NC; SPSS; SPSS Inc, Chicago, Ill) for analysis. Normal distribution of 


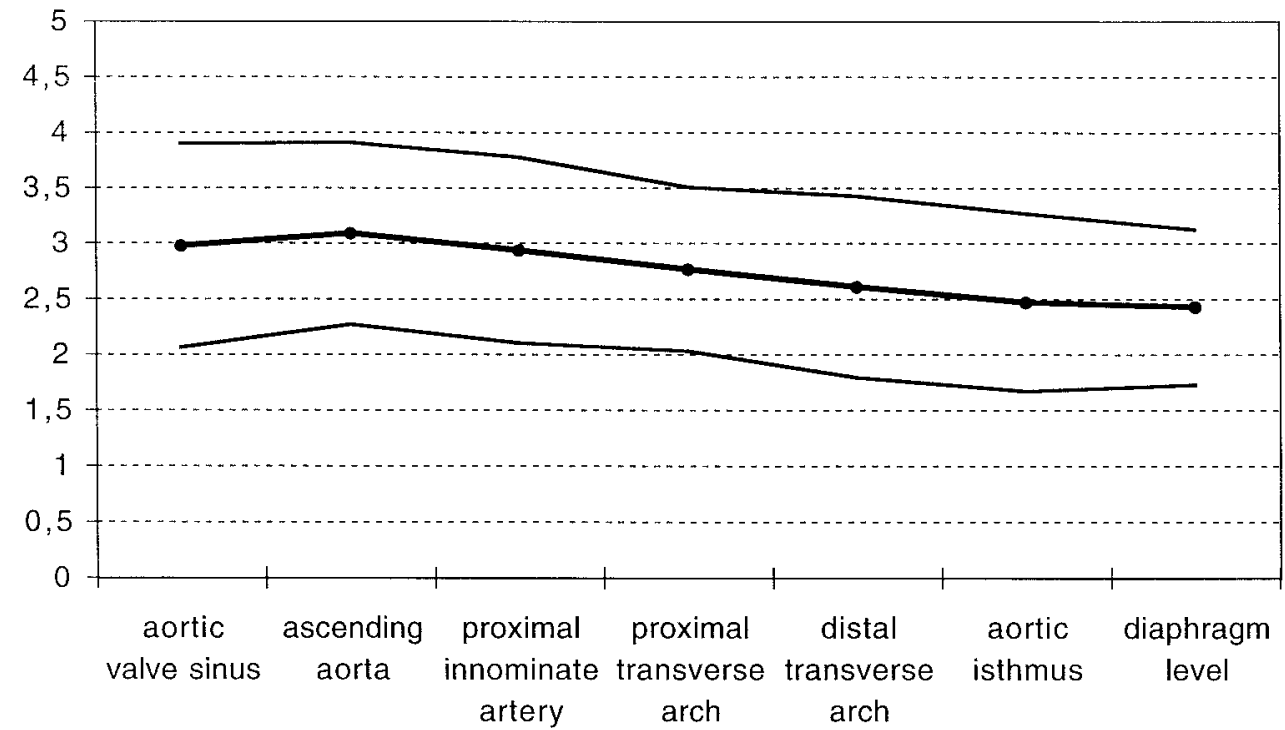

Figure 2. Mean aortic diameters at various levels measured by helical CT in 70 adults. Thin lines represent \pm 2 SD, representing $95 \%$ reference area.

the diameters was assumed. To analyze the changes of the diameters along the course of the aorta, paired $t$ tests of neighboring diameters were used. Analysis of variance was performed to test for the influences on the aortic diameters of sex, age, weight, height, and body surface area. Variables that showed an influence were analyzed in detail with 2 -sided $t$ tests, additional analyses of variance, or multiple regression analysis.

\section{Results}

Mean aortic diameters and their SD band (mean \pm 2 SD), representing a 95\% reference area, are shown in Figure 2. Aortic diameter increased significantly from the aortic valve sinus to the ascending aorta and decreased continuously to the isthmus. The difference between the diameters at the isthmic and diaphragmatic levels failed to be significant.

Analysis of variance revealed no influence of weight, height, or body surface area, but it did reveal influences of sex and age. The detailed analysis showed that the influence of sex reached significance only for the ascending aorta, the distal transverse arch, and the diaphragmatic level (Table 2).

Age as an influence was also analyzed in detail by regression analysis (Table 3 ). There was a significant increase of the aortic diameters at all intrathoracic levels throughout adult life. Diameters of the aorta according to age are plotted in Figure 3.

The aortic ratios normalized to the diameters at the diaphragmatic level are shown in Figure 4. Analysis of variance revealed no significant influence of any of the investigated factors.

\section{Discussion}

The aorta is a complex vascular structure with many different functions varying along its course. The thoracic aorta provides compliance with elastic recoil to maintain blood pressure and antegrade blood flow throughout diastole. The more distal abdominal aorta functions mainly as a conduit. The varying functions are reflected in the histologic structure of the aorta. The elastin/collagen ratio is highest in the thoracic part and decreases distally. With age, the aortic wall structure changes. Elastin fragmentation, fibrosis, and media necrosis occur in the aorta as signs of aging. ${ }^{12}$ Furthermore, various diseases alter aortic structure and function ${ }^{13-15}$ and may cause obstruction or dilatation of the aorta. Both obstruction and dilatation may be circumscript, segmental, or spread throughout the entire aorta.

Different methods have been used to assess and follow up such structural changes. Management decisions often depend strongly on the comparison of measured aortic diameters with normal values. Especially for the definition and classification of structural abnormalities, such as aneurysm, aortomegaly, ectasia, stenosis, coarctation, and hypoplasia, the knowledge of normal aortic diameters at different levels is essential. Reference values have to be built up for each method. ${ }^{16}$ With a standard method such as helical CT, one should not use normal values obtained from such other techniques as echocardiography, magnetic resonance imaging, angiography, or even postmortem studies, although differences in measurement should be small and confined to fundamental differences in image analysis or acquisition. We therefore present nomograms for aortic dimensions at various intrathoracic levels in healthy adults according to helical CT data (Figure 2).

Comparison of the presented helical CT data with data from such other imaging methods as echocardiography, angiography, conventional axial CT, and magnetic reso- 
TABLE 2. Aortic diameters at various thoracic levels in adults measured with helical CT

\begin{tabular}{|c|c|c|c|c|}
\hline Aortic level & $\begin{array}{c}\text { Female } \\
(n=24)\end{array}$ & $\begin{array}{c}\text { Male } \\
(n=46)\end{array}$ & $\begin{array}{c}\text { Total } \\
(n=70)\end{array}$ & $P$ value \\
\hline Aortic valve sinus & $2.88 \pm 0.38$ & $3.04 \pm 0.50$ & $2.98 \pm 0.46$ & .196 \\
\hline Ascending aorta (maximum) & $2.90 \pm 0.34$ & $3.20 \pm 0.42$ & $3.09 \pm 0.41$ & .004 \\
\hline Proximal to innominate artery & $2.82 \pm 0.36$ & $3.00 \pm 0.44$ & $2.94 \pm 0.42$ & .095 \\
\hline Proximal transverse arch & $2.65 \pm 0.27$ & $2.84 \pm 0.40$ & $2.77 \pm 0.37$ & .044 \\
\hline Distal transverse arch & $2.40 \pm 0.29$ & $2.72 \pm 0.43$ & $2.61 \pm 0.41$ & .001 \\
\hline Aortic isthmus & $2.32 \pm 0.36$ & $2.55 \pm 0.39$ & $2.47 \pm 0.40$ & .016 \\
\hline Diaphragm & $2.27 \pm 0.31$ & $2.51 \pm 0.34$ & $2.43 \pm 0.35$ & .005 \\
\hline
\end{tabular}

Measurements are expressed as mean \pm SD in centimeters.

TABLE 3. Regression analysis of the influence of age on aortic diameters at various thoracic levels in $\mathbf{7 0}$ adults measured with helical CT

\begin{tabular}{|c|c|c|c|c|c|}
\hline Aortic level & $\begin{array}{l}\text { Slope } \\
(\mathrm{cm} / \mathrm{y})\end{array}$ & $\begin{array}{l}\text { Intercept } \\
\text { (cm) }\end{array}$ & $r$ & $r^{2}$ & $P$ value \\
\hline Aortic valve sinus & 0.0124 & 2.36 & 0.443 & 0.196 & $<.001$ \\
\hline Ascending aorta (maximum) & 0.0153 & 2.32 & 0.612 & 0.375 & $<.001$ \\
\hline Proximal to innominate artery & 0.0136 & 2.26 & 0.536 & 0.287 & $<.001$ \\
\hline Proximal transverse arch & 0.0117 & 2.19 & 0.524 & 0.274 & $<.001$ \\
\hline Distal transverse arch & 0.0118 & 2.02 & 0.474 & 0.224 & $<.001$ \\
\hline Aortic isthmus & 0.0078 & 2.08 & 0.327 & 0.106 & .006 \\
\hline Diaphragm & 0.0124 & 1.80 & 0.590 & 0.348 & $<.001$ \\
\hline
\end{tabular}

Slope describes the increase during adulthood.

nance imaging is difficult, because these data are sparse and sometimes only focus on specific segments of the aorta.

Transthoracic echocardiography in adults is mostly restricted to the aortic root for technical reasons. Reference values exist only for children and young adults. ${ }^{17-20} \mathrm{Re}$ ported aortic diameters of adolescents are smaller than those presented in our study. This difference could be due to the younger age of the investigated population.

Transesophageal echocardiography is the method of choice to visualize the ascending and descending thoracic aorta in patients with aortic dissection or after thoracic trauma, ${ }^{2}$ whereas the transesophageal assessment of the aortic arch is limited. Nevertheless, comprehensive transesophageal echocardiographic data regarding the size of the normal thoracic aorta are still lacking.

In some institutions angiography is still considered the criterion standard for visualization of the aorta. Although Clarkson and associates ${ }^{10}$ set up normal values for all levels of the intrathoracic aorta in children 6 years and younger, normal angiographic values for adults are still absent.

For years, conventional axial CT was also used to visualize the thoracic aorta. Because only axial planes are available, however, the diameter of the aortic arch and sometimes that of the ascending aorta are difficult to measure correctly. Therefore only reference diameters for the ascending and descending aorta exist. ${ }^{11}$ The published values for the ascending and more cranial descending aorta are higher than in our series, with only the values at the diaphragmatic level similar to our results. This overestimates the ascending aorta by as much as $6 \mathrm{~mm}$, or $21 \%$. The reason is probably that measurements were only taken in the axial plane, not strictly perpendicular to the aortic wall.

In the last years magnetic resonance imaging has been used increasingly for the follow-up of patients with chronic aortic disease. ${ }^{21-23}$ However, no normal values for aortic dimensions in adults are available for this method either.

In this study we showed that in adults aortic diameters vary with age and sex but are independent of weight, height, and body surface area. Sex has only a weak influence, with mean values for women and men differing no more than 3.2 $\mathrm{mm}$ at any level, which is minimal compared to normal variation (within $1 \mathrm{SD}$ ).

Concerning the influence of age, this study confirms data available from conventional CT. This study matches with the study of Aronberg and associates, ${ }^{11}$ which showed that aortic diameters increase about $1 \mathrm{~mm}$ per decade during adulthood. For the abdominal aorta, Pearce and colleagues ${ }^{24}$ discussed a multifactorial pathophysiologic picture. The most important factors are plaque formation and elastin fragmentation by elastolytic enzymes without elastin formation, which ceases after the first few years of life. For the increasing diameters in the thoracic aorta, the elastic components might be more pronounced than in the abdominal aorta. 

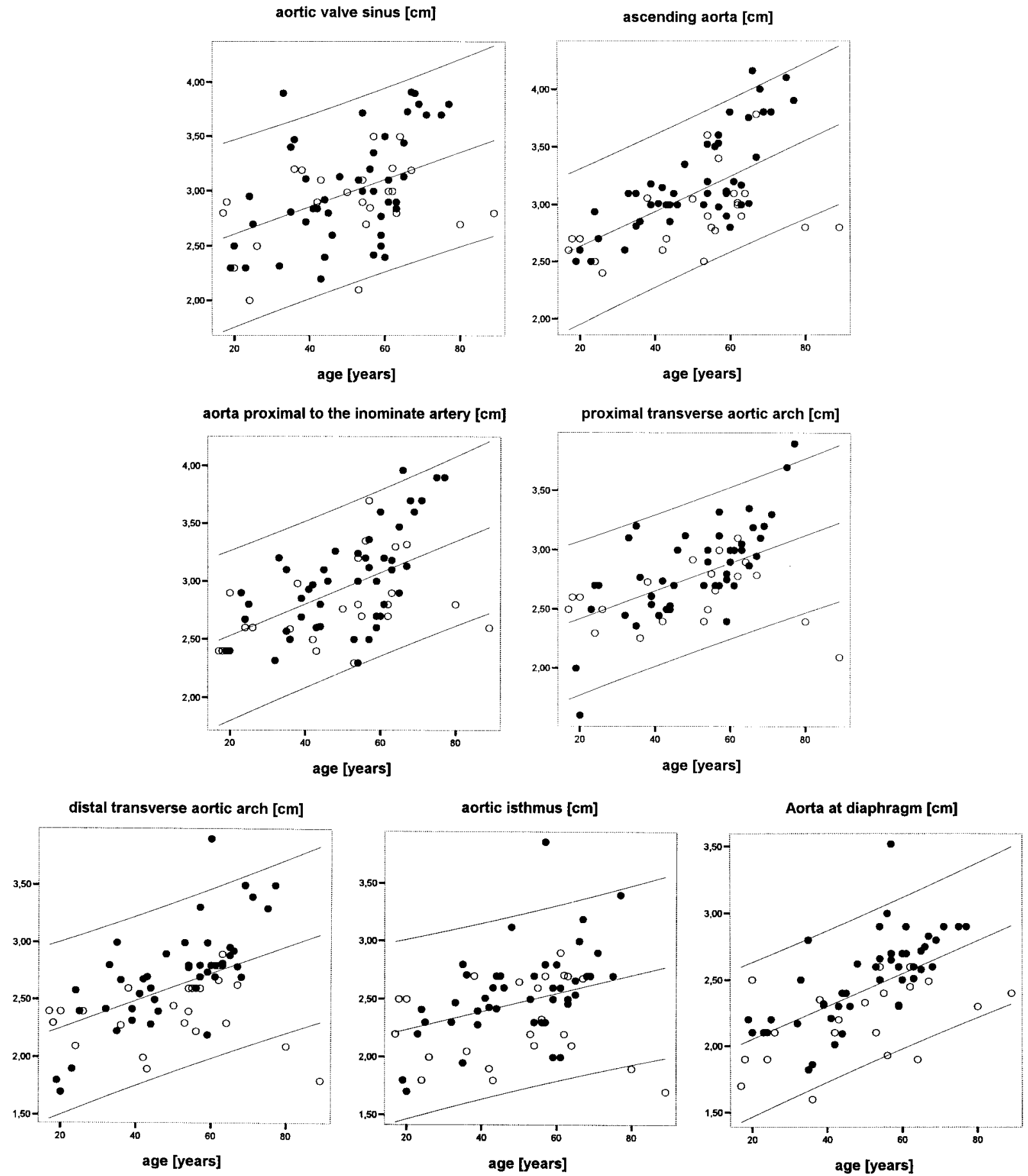

Figure 3. Age-related means and $95 \%$ reference bands of internal diameter (in centimeters) of thoracic aorta at various levels, derived from helical CT measurements in 70 adults 17-89 years old. Open circles represent women; closed circles represent men.

Any influence of anthropometric data on aortic diameters was not apparent in this series. This is consistent with other studies, which similarly did not show any influence of height, weight, or body surface area on aortic dimensions in adults when these data were adjusted for age and sex. ${ }^{11,18}$ Only studies that included children used diameters adjusted for body surface area, never proving whether that is appropriate in adults. 


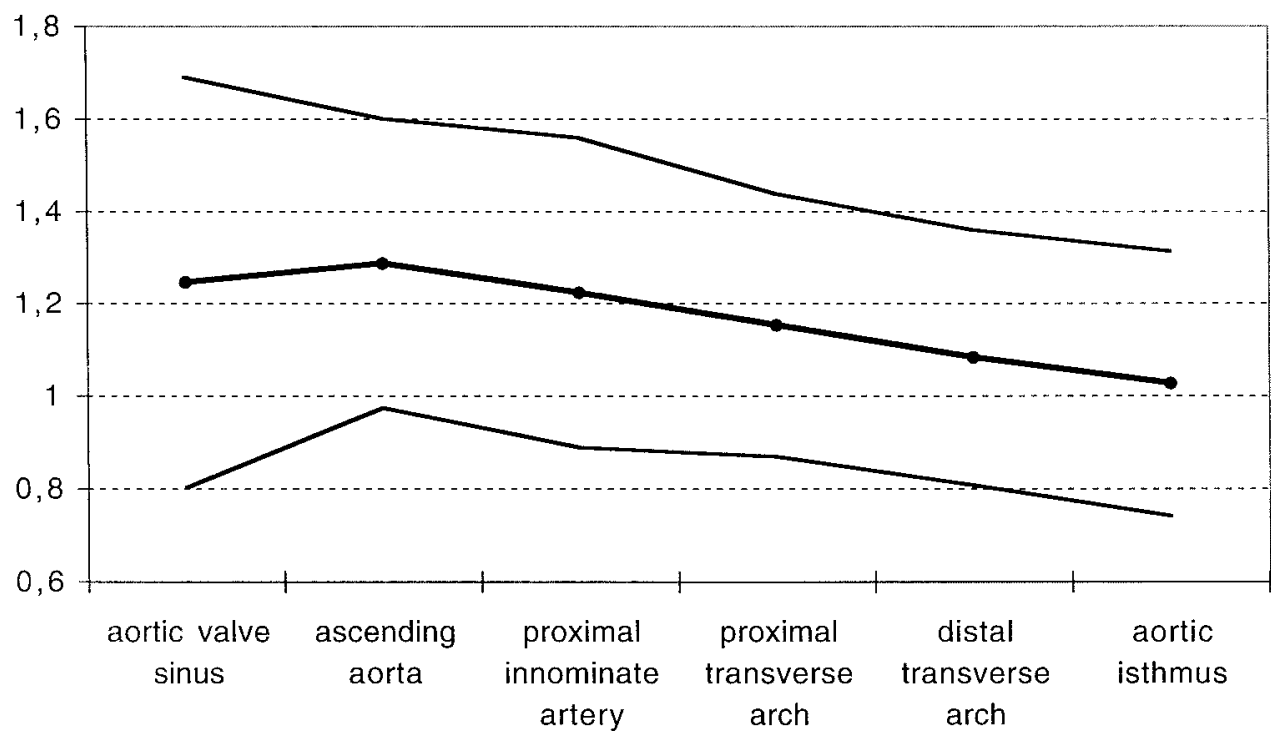

Figure 4. Mean ratios of aortic diameters at various levels normalized to diameter at diaphragm as measured by helical CT in 70 adults. Thin lines represent \pm 2 SD, representing 95\% reference area.

In view of the lack of normal values, it has been suggested that the ratio of a given aortic diameter to that at a reference level be used to define stenosis or dilatation. ${ }^{9}$ Either the ascending aorta or the aorta at diaphragmatic level was selected as the reference level. This is questionable, however, because the aortic root is often subject to pathologic changes, not only in patients with connective tissue disease but even in patients with bicuspid aortic valve, ${ }^{25}$ aortic stenosis, or atherosclerosis. In our opinion, it is therefore more appropriate to choose the diaphragmatic level as the reference level, because aneurysms and hypoplasia are rarely found there. Figure 4 shows those ratios that are independent of age, sex, weight, height, and body surface area in our adult study population. Therefore this approach seems to be ideal as long as the aorta at the diaphragmatic level is free of pathologic changes.

On the basis of these data, stenosis and dilatation of longer aortic segments, such as vessel hypoplasia, strictures, and aortomegaly, should be defined as a deviation of more than 2 SD from the normal value. Localized aneurysm should continue to be defined as a greater than $50 \%$ difference from the diameter of the adhering normal vessel, ${ }^{16}$ and discrete stenosis such as coarctation should be defined as a greater than $60 \%$ reduction in the diameter that Clatworthy and colleagues ${ }^{26}$ demonstrated to be hemodynamically significant.

\section{References}

1. Trerotola SO. Can helical CT replace aortography in thoracic trauma? [editorial] Radiology. 1995;197:13-5.

2. Sommer T, Fehske W, Holzknecht N, Smekal AV, Keller E, Lutterbey $\mathrm{G}$, et al. Aortic dissection: a comparative study of diagnosis with spiral
CT, multiplanar transesophageal echocardiography, and MR imaging. Radiology. 1996;199:347-52.

3. Kaemmerer H, Mugge A, Oelert F, Prokop M, Rapp U, Schoehl W, et al. [Evaluation of the aorta and supra-aortic vessels with spiral CT and 3-dimensional vascular reconstruction after operation of aortic isthmus stenosis]. Z Kardiol. 1994;83:775-83.

4. Park JH, Chung JW, Im JG, Kim SK, Park YB, Han MC. Takayasu arteritis: evaluation of mural changes in the aorta and pulmonary artery with CT angiography. Radiology. 1995;196:89-93.

5. Chung JW, Park JH, Im JG, Chung MJ, Han MC, Ahn H. Spiral CT angiography of the thoracic aorta. Radiographics. 1996;16:811-24.

6. Hopkins KL, Patrick LE, Simoneaux SF, Bank ER, Parks WJ, Smith SS. Pediatric great vessel anomalies: initial clinical experience with spiral CT angiography. Radiology. 1996;200:811-5.

7. Becker C, Soppa C, Fink U, Haubner M, Muller-Lisse U, Englmeier $\mathrm{KH}$, et al. Spiral CT angiography and 3D reconstruction in patients with aortic coarctation. Eur Radiol. 1997;7:1473-7.

8. Yamada I, Nakagawa T, Himeno Y, Numano F, Shibuya H. Takayasu arteritis: evaluation of the thoracic aorta with $\mathrm{CT}$ angiography. Radiology. 1998;209:103-9.

9. Moulaert AJ, Bruins CC, Oppenheimer-Dekker A. Anomalies of the aortic arch and ventricular septal defects. Circulation. 1976;53:1011-5.

10. Clarkson PM, Brandt PW. Aortic diameters in infants and young children: normative angiographic data. Pediatr Cardiol. 1985;6:3-6.

11. Aronberg DJ, Glazer HS, Madsen K, Sagel SS. Normal thoracic aortic diameters by computed tomography. J Comput Assist Tomogr. 1984; 8:247-50.

12. Schlatmann TJ, Becker AE. Histologic changes in the normal aging aorta: implications for dissecting aortic aneurysm. Am J Cardiol. 1977;39:13-20.

13. Stefanadis C, Stratos C, Vlachopoulos C, Marakas S, Boudoulas H, Kallikazaros I, et al. Pressure-diameter relation of the human aorta: a new method of determination by the application of a special ultrasonic dimension catheter. Circulation. 1995;92:2210-9.

14. Stefanadis C, Dernellis J, Vlachopoulos C, Tsioufis C, Tsiamis E, Toutouzas K, et al. Aortic function in arterial hypertension determined by pressure-diameter relation: effects of diltiazem. Circulation. 1997; 96:1853-8.

15. Stefanadis C, Dernellis J, Tsiamis E, et al. Aortic stiffness as a risk factor for recurrent acute coronary events in patients with ischaemic heart disease. Eur Heart J. 2000;21:390-6. 
16. Johnston KW, Rutherford RB, Tilson MD, Shah DM, Hollier L, Stanley JC. Suggested standards for reporting on arterial aneurysms. Subcommittee on Reporting Standards for Arterial Aneurysms, Ad Hoc Committee on Reporting Standards, Society for Vascular Surgery and North American Chapter, International Society for Cardiovascular Surgery. J Vasc Surg. 1991;13:452-8.

17. Snider AR, Enderlein MA, Teitel DF, Juster RP. Two-dimensional echocardiographic determination of aortic and pulmonary artery sizes from infancy to adulthood in normal subjects. Am J Cardiol. 1984; 53:218-24.

18. Reed CM, Richey PA, Pulliam DA, Somes GW, Alpert BS. Aortic dimensions in tall men and women. Am J Cardiol. 1993;71:608-10.

19. Roman MJ, Devereux RB, Kramer-Fox R, O’Loughlin J. Twodimensional echocardiographic aortic root dimensions in normal children and adults. Am J Cardiol. 1989;64:507-12.

20. Rozendaal L, Groenink M, Naeff MS, Hennekam RC, Hart AA, van der Wall EE, et al. Marfan syndrome in children and adolescents: an adjusted nomogram for screening aortic root dilatation. Heart. 1998; 79:69-72.

21. Simpson IA, Chung KJ, Glass RF, Sahn DJ, Sherman FS, Hesselink J. Cine magnetic resonance imaging for evaluation of anatomy and flow relations in infants and children with coarctation of the aorta. Circulation. 1988;78:142-8

22. Kaemmerer H, Ehrenheim C, Wilken W, Burchert W, Luhmer I, Hundeshagen $\mathrm{H}$, et al. Klinische und kernspintomographische Verlaufskontrollen bei Kindern nach Dilatation einer Aortenisthmusstenose (CoA). Z Kardiol. 1990;79:766-73.

23. Kaemmerer H, Mugge A, Prokop M, Schirg E, Oelert F, Bahlmann J, et al. [Diagnostic imaging in follow-up of surgically treated stenosis of the aortic isthmus in adolescents and adults]. Wien Med Wochenschr. 1995;145:206-10.

24. Pearce WH, Slaughter MS, LeMaire S, Salyapongse AN, Feinglass J, McCarthy WJ, et al. Aortic diameter as a function of age, gender, and body surface area. Surgery. 1993;114:691-7.

25. Nistri S, Sorbo MD, Marin M, Palisi M, Thiene G. Aortic root dilatation in young men with normally functioning bicuspid aortic valves. Heart. 1999;82:19-22.

26. Clatworthy HW, Sako Y, Chisholm TC. Thoracic aortic coarctation: Its experimental production in dogs, with special reference to technical methods capable of inducing significant intraluminal stenosis. Surgery. $1950 ; 28: 245-73$.

\section{JTCVS On-Line Manuscript Submission and Review \\ Please visit http://www.editorialmanager.com/jtcvs/}

Effective September 15, 2001, authors and reviewers may submit manuscripts and reviews electronically via Editorial Manager, our new Web-based system with full electronic submission, review, and status update capabilities.

As we move from paper to electronic submissions, the Editorial Office will make proxy submissions of all manuscripts accompanied by a diskette containing the electronic files of the text, tables, and figures. Editors, authors, and reviewers will receive automatic e-mails when significant events occur.

We strongly encourage all authors and reviewers to use Editorial Manager. Although we will continue to accommodate the submission of paper manuscripts for some months, our goal is to be completely electronic within 9 to 12 months.

All individuals currently in our database for whom we have e-mail addresses will receive via e-mail a system-assigned username and password that can be used to log in to the system without prior registration. All those not receiving the e-mail must register the first time they use the system.

As with any broad systemic change, the conversion to the new system will take some time to complete. We ask your patience as we replace our in-office database with the new system. We also encourage you to take advantage of the speed and efficiency that the new system will provide for us all: editor, author, reviewer, and publisher. 